\title{
Effect of Ramadan Fasting on Anthropometric Measures and Metabolic Profiles among Type 2 Diabetic Subjects
}

\author{
Ajit Kumar Paul ${ }^{1}$, Murshed Ahamed Khan ${ }^{2}$, Md. Fariduddin ${ }^{3}$ \\ Received: June 12, 2014 Accepted: April 21, 2015 \\ doi: http://dx.doi.org/10.3329/jemc.v5i2.23382
}

\begin{abstract}
Background: Fasting from dawn to dusk during the month of Holy Ramadan is obligatory for all healthy adult Muslims. Individuals are exempted from fasting if they are suffering from an illness that could be adversely affected by fasting. Although The Quran exempts sick people from fasting, many Muslim diabetic patients may not perceive themselves as sick and are keenly interested to fast. But they fast without proper medical guidance exposing themselves to certain risks as a direct consequence of fasting. So we designed this study to assess the impact of fasting during Ramadan and to evaluate the effects of fasting on their biochemical profiles in patients with diabetes. Objective: The objective of this study was to investigate whether Ramadan fasting has any effect on body weight, blood pressure, fasting glucose, HbAlc, serum lipids, serum creatinine among type 2 diabetic patients. Materials and Methods: Fifty two stable outpatients with type 2 diabetes with intention to fast were studied in the month of Ramadan 1434 Hijri calendar year $\left(11^{\text {th }}\right.$ July to $9^{\text {th }}$ August, 2013) at two points of time: one week before Ramadan (visit 1) and within last 3 days before the end of Ramadan (visit 2). During each visit the height, body weight and blood pressure were recorded. Blood samples were collected for fasting glucose, HbAlc, total cholesterol, triglyceride, high density and low density lipoprotein cholesterol and creatinine. Data were analyzed by Student's paired t-test using SPSS system and results were expressed as mean $\pm S D$. Probability values were considered to be significant if it was less than 0.05. Results: There were 30 $(62.8 \%)$ males and $22(37.2 \%)$ females with a mean age of $54.7 \pm 11.55$ (range 35-80) years and mean duration of diabetes was $5.5 \pm 5.2$ years (range 9 months -18 years). In this study mean weight of the patients decreased significantly from $60.5 \pm 12.6 \mathrm{~kg}$ to $58.5 \pm 11.3 \mathrm{~kg}(p<0.001)$. Blood pressure reduced but not significantly. Fasting blood glucose showed significant reduction from $10.7 \pm 4.2$ to $8.9 \pm 3.7 \mathrm{mmol} / \mathrm{L}(p=0.002)$ at the end of the study though HbAlc showed no significant change. Lipid profile and serum creatinine values did not show any significant change.

Conclusion: The effects of fasting during Ramadan on stable diabetic patients are minimal. So, stable diabetic patients can fast during Ramadan without significant detrimental effects.
\end{abstract}

Key words: Ramadan; Diabetes; Anthropometric measures; Metabolic profiles

J Enam Med Col 2015; 5(2): 93-98

\section{Introduction}

Fasting in Ramadan is one of the five pillars of Islam. During this month all adult Muslims abstain not only from eating, drinking, smoking and sexual relations but also from oral drug intake and nutritional intravenous

injection from sunrise (dawn) to sunset. ${ }^{1}$ Diabetes is a metabolic disorder characterized by high level of blood glucose resulting from defects in insulin production and/or insulin action.

1. Senior Consultant, Diabetic Hospital, Comilla

2. Medical Officer, Department of Endocrinology, Bangabandhu Sheikh Mujib Medical University, Dhaka

3. Professor, Department of Endocrinology, Bangabandhu Sheikh Mujib Medical University, Dhaka

Correspondence Murshed Ahamed Khan,Email: makhan1205@gmail.com 
More than 382 million people have diabetes in the world and there were more than 72 million adults with diabetes in 2013 and it is expected to exceed 123 million by $2035 .^{2}$ There were 5.5 million cases of diabetes in Bangladesh in 2012 and this will reach 11 million by the year 2030. Various studies in Bangladesh have reported that the prevalence of diabetes is from 4 to $13 \%$ among adults with some variations by rural and urban settings. ${ }^{3-5}$ There are about 1 billion Muslims in the world and more than 50 million people with diabetes fast during Ramadan. ${ }^{6}$

Fasting is obligatory for all healthy adult Muslims during Ramadan. ${ }^{1,7}$ Eating and drinking are permitted only after sunset. Muslims typically take two main meals - after sunset and just before dawn. Individuals are exempted from fasting if they are suffering from an illness that could be adversely affected by fasting. During Ramadan month, type 2 DM (T2DM) patients are exposed to changes in meal times, types of foods, use of medication and daily lifestyle and these changes may affect their health. Although The Quran exempts sick people from fasting, many Muslim diabetic patients may not perceive themselves as sick and are keenly interested to fast. The largest epidemiological study of Muslims with diabetes in 13 Muslim countries (EPIDIAR STUDY) showed that $43 \%$ of patients with type 1 and $79 \%$ of patients with type 2 diabetes fasted during Ramadan. ${ }^{8}$ Most of the Muslim diabetic patients still prefer to fast without medical guidance exposing themselves to certain risks as a direct consequence of fasting. ${ }^{9}$ Most Muslim religious authorities accept that if a person is advised by a trusted health professional that fasting is harmful to his or her health, then that person is exempted from fasting. ${ }^{10}$ In a large observational study, patients who fasted during Ramadan without attending a structured educational session had a four-fold increase in hypoglycemic events whereas those who attended an educational program focusing on Ramadan had a significant decrease in hypoglycemic events. ${ }^{11}$ This entails improving patient education as well as tailoring the treatment to meet the needs of this group of people with diabetes to minimize the possible risks. ${ }^{12}$ So, having diabetes does not mean that patients cannot fast.

Ramadan fasting affects anthropometric and metabolic parameters of the body. Certain studies have attempted to correlate religious fasting and possible health benefits. ${ }^{14-16}$ Clinical and biochemical effects of fasting among diabetics have been studied before but the results have not been conclusive. Studies have reported substantial weight loss, signs of dehydration, raised serum concentrations of uric acid and cholesterol during Ramadan. ${ }^{17}$ Other studies show Ramadan fasting induces a marked increase in high-density lipoprotein cholesterol and decrease in low-density lipoprotein cholesterol. ${ }^{18,19}$ Moreover, variation in these parameters occurs in different countries, societies, cultures which may be due to variation in dietary pattern during Ramadan fast. On the other hand, physicians commonly face the difficult task of advising T2DM patients whether it is safe to fast as well as recommending the dietary and drug regimens which diabetics should follow if they decide to fast. So, diabetic patients need a special attention to monitor any change that affects their health in order to suggest the proper care for them during Ramadan.

The aim of this study was to assess the impact of fasting during Ramadan on the clinical status of patients with diabetes and to evaluate the effects of fasting on their biochemical profiles.

\section{Materials and Methods}

This was a prospective observational study conducted in Comilla Diabetic Hospital, a tertiary care specialized diabetic hospital in Bangladesh. The subjects were diabetic patients who agreed to participate in this study and informed consent was taken accordingly. The study was approved by the local ethical committee. Patients who were stable on diet, oral hypoglycemic drugs or insulin were included in this study. Patients less than 18 years old, patients with diabetic ketoacidosis or hyperosmolar hyperglycemic state, recurrent or severe hypoglycemia in the past 3 months, hypoglycemic unawareness, any degree of nephropathy, retinopathy, ischemic heart disease, poor glycemic control and other chronic diseases (e.g. tuberculosis) and pregnant and lactating women were excluded from the study.

The study was carried out in the month of Ramadan of 1434 Hijri calendar year ( $11^{\text {th }}$ July to $9^{\text {th }}$ August, 2013) at two points of time; one week before Ramadan (visit 1) and within last three days before the end of Ramadan (visit 2). All the participants had to fast a minimum of 25 days.

During each visit the height and body weight were recorded and blood specimens were collected for fasting blood sugar, HbA1c, serum lipids and serum creatinine. Hypoglycemic events and other complications of fasting were recorded in visit 2 . 
The aim of pre-Ramadan visit (visit1) was to assess the physical well being of patients, assess their diabetes control and educate them in adjusting their diet and modification of timing and doses of medication during the month of Ramadan. They were also educated about the warning symptoms of hypoglycemia, dehydration, and any other possible complications. They were advised to break fast as soon as any such complication was noted. However they were instructed to carry on with their usual living habits and physical activity. All study population was advised to take a well planned $\operatorname{diet}^{20}$ after fasting (iftar) and to pray tarawi prayer regularly. In this study, tarawi prayer was the only physical exercise done by study subjects. Blood specimens were collected for baseline blood levels during visit 1 and within last three days before the end of Ramadan (visit 2) in fasting state (one hour before iftar). During visit 2 they were told to revert back to prior schedule after the Ramadan.

With all aseptic precautions about $5 \mathrm{~mL}$ blood was drawn in a fasting state from all participants in each visit. Serum was separated by centrifugation at 4000 round/minute for 10 minutes. Serum was used to estimate total cholesterol (TC), triglyceride (TG), high-density lipoprotein cholesterol (HDL-C), creatinine, and blood glucose level. Low-density lipoprotein cholesterol (LDL-C) in $\mathrm{mg} / \mathrm{dL}$ was calculated by using Friedewald's formula. ${ }^{21}$ Data were analyzed using statistical package of social sciences (SPSS) system (version 16.0). Results were expressed as mean $\pm \mathrm{SD}$ and analyzed by Student's paired t-test. Probability values $(\mathrm{p})$ were considered to be significant if it was less than 0.05 .

\section{Results}

Fifty five patients were enrolled initially for the study. Three patients were excluded as they could not complete fasting a minimum of 25 days. Finally there were 52 diabetic patients, 30 males (62.8\%) and 22 females (37.2\%) with a mean age of $54.7 \pm$ 11.55 (35-80) years. The mean duration of diabetes was $5.5 \pm 5.2$ years (9 months-18 years). Thirty five patients $(67.3 \%)$ were taking oral hypoglycemic agent, 7 patients $(13.5 \%)$ were on insulin and remaining 10 patients $(19.2 \%)$ were on only dietary measures. The details of anthropometric and laboratory values are summarized in Table I.

Table I: Comparison of anthropometric and laboratory values between visit 1 and visit 2

\begin{tabular}{|l|c|c|c|}
\hline Variables & Visit 1 & Visit 2 & p values \\
\hline Weight $(\mathrm{Kg})$ & $60.5 \pm 12.6$ & $58.5 \pm 11.3$ & $<0.001$ \\
\hline SBP $(\mathrm{mm}$ of $\mathrm{Hg})$ & $130.83 \pm 14.86$ & $125.00 \pm 17.56$ & 0.170 \\
\hline DBP $(\mathrm{mm}$ of $\mathrm{Hg})$ & $78.33 \pm 5.92$ & $75.33 \pm 7.18$ & 0.083 \\
\hline FBG/1HBI $(\mathrm{mmol} / \mathrm{L})$ & $10.7 \pm 4.2$ & $8.9 \pm 3.7$ & 0.002 \\
\hline Total chol $(\mathrm{mg} / \mathrm{dL})$ & $224 \pm 55.8$ & $218 \pm 51.5$ & 0.391 \\
\hline TG $(\mathrm{mg} / \mathrm{dL})$ & $189.87 \pm 53.62$ & $175.80 \pm 51.63$ & 0.305 \\
\hline HDL-C $(\mathrm{mg} / \mathrm{dL})$ & $55 \pm 14.3$ & $56.6 \pm 11.2$ & 0.47 \\
\hline LDL-C $(\mathrm{mg} / \mathrm{dL})$ & $103.86 \pm 6.18$ & $111.97 \pm 4.24$ & 0.26 \\
\hline Creatinine $(\mathrm{mg} / \mathrm{dL})$ & $1.12 \pm 0.10$ & $1.11 \pm 0.14$ & 0.755 \\
\hline HBA1c $(\%)$ & $8.44 \pm 1.05$ & $8.47 \pm 1.11$ & 0.915 \\
\hline
\end{tabular}

1 HBI, 1 hour before iftar

In this study there was significant weight reduction $(\mathrm{p}<0.001)$ by the end of Ramadan fast. Blood pressure also reduced but it was not significant. Fasting blood sugar showed significant reduction $(\mathrm{p}=0.002)$ at the end of the study but HbA1c showed no significant change. This may be due to short duration of study period (1 month) to see any effect on HbA1c. Serum lipid profile and creatinine values did not show any significant changes. There was no hypoglycemic episode.

\section{Discussion}

This study was conducted in Bangladeshi population to observe the effects of fasting on anthropometric measures and metabolic profiles among T2DM patients.

In this study, the mean weight of the patients reduced significantly during the month of Ramadan. This was probably due to a decrease in the number of meals (two meals instead of three meals) that significantly contributed to reduce the amount of calorie intake during Ramadan as compared to pre-Ramadan period. Loss of the midday meals which is the principal meals in our dietary pattern may be another cause. Review of some literatures shows controversy about weight changes in diabetics during Ramadan. ${ }^{22,23}$ Some studies show weight gain instead of loss while others show no change. ${ }^{24-26}$ It has 
been attributed to reduced daily activities by diabetics for fear of hypoglycemia. It has also been reported that overweight persons lose more weight than normal or underweight subjects. ${ }^{27}$

The effect of Ramadan fasting on lipid profile is different in published articles and this may be due to a change in the dietary regimen during Ramadan, decreased activity and some cultural norms. This is attributed by the researcher to higher consumption of dietary fat, especially the saturated fatty acids and dietary cholesterol during the month. A previous study reported that dietary fat, particularly saturated fat, was higher in the diet during Ramadan month. ${ }^{28}$ Similar findings were found in the study by Chamakhi et $\mathrm{al}^{29}$ where there was an increase in total cholesterol (TC) levels during Ramadan month among T2DM patients. Another study found significantly increased TC levels with the high fat diet and compared to the levels obtained after the high $\mathrm{CHO}$ diet. ${ }^{30}$ In the present study there is no significant change in TC level which is similar to the study done by Dehgan et $\mathrm{al}^{31}$ who found no change in TC levels during Ramadan month among T2DM patients. In contrast to the present findings, Gumaa et $\mathrm{al}^{32}$ found a significant decrease in TC levels among patients with T2DM.

In this study, there was no difference in serum triglyceride levels between pre-Ramadan and within last three days before the end of Ramadan. This finding is consistent with that found by Sulimani et al. ${ }^{26}$ This may be due to a well structured dietary plan and also regular exercise (tarawi prayer). In some studies, it increased significantly during Ramadan. ${ }^{32,33}$ Elevated blood triglyceride (TG) levels may be due to the consumption of high-carbohydrate diets accompanied by less exercise during this month. In contrast, Yarahmadi et $\mathrm{al}^{34}$ reported a statistically significant decrease in blood TG levels during the month of Ramadan among T2DM patients.

LDL-C level in T2DM with fasting showed inconsistent result in majority of studies. One study showed significant increase ${ }^{33}$, another showed significant decrease $^{35}$ and another study revealed no change. ${ }^{36}$ In this study, there is no change in LDL-C level in T2DM during fasting.

Like TG and LDL-C, HDL-C level in T2DM showed no significant changes during Ramadan. This result is similar to the study done by Yarahmadi et al in T2DM patients. ${ }^{34}$ Toth $^{37}$ showed significant reduction in HDL$\mathrm{C}$ level which may be due to decline in physical activity and sedentary lifestyle during the Ramadan. Another cause of physical inactivity in diabetic patients may be fear of hypoglycemia. In this study, there was no change in HDL-C level during fasting which may be due to regular tarawi prayer. So, this can be recommended as substitution for regular walking during the period of Ramadan in T2DM. Some studies showed statistically significant increase in HDL-C level in T2DM during Ramadan. ${ }^{36,38}$

In this study, fasting blood glucose (FBG) level of preRamadan period was compared with blood glucose one hour before iftar. There is statistically significant reduction in FBG level by the end of Ramadan month compared to pre-Ramadan among T2DM patients with no change in HbAlc. This may be due to decrease in the number of meals during Ramadan, and in turn to low calorie intake and the consequent depletion in glycogen stores. Few studies support this interpretation ${ }^{39,40}$, but Mahboob et al showed no statistically significant changes in FBG levels at the end of Ramadan. ${ }^{41}$ These controversial data regarding the impact of fasting on blood sugar can be due to a quantitative and qualitative food diversity consumed by the patients during the period of fasting, but also to the difference in the eating habit of the studied populations. Other factors such as the regular taking of medicines, the daily length of fasting, the individual variations in the quantity of blood glucose and the lack of physical exercise were also found to influence the outcome. ${ }^{42}$

The present finding of HbAlc levels among study subjects was consistent with the study done by Yarahmadi et $\mathrm{al}^{34}$. On the other hand, other research studies have reported a statistically significant decrease in blood HbA1c levels during the month of Ramadan among T2DM patients. ${ }^{41}$

Mafauzy et $\mathrm{al}^{22}$ showed that Ramadan fasting was associated with no statistically significant change in serum creatinine levels among T2DM patients which is similar to this study. But Saada et $\mathrm{al}^{43}$ found statistically significant reduction in blood creatinine levels among T2DM patients.

The results of this study show that the effects of fasting during Ramadan on stable diabetic patients are minimal. 
Furthermore, it is associated with weight loss and improvement in the overall diabetic control. Stable patients with diabetes can fast during the month of Ramadan safely.

\section{Acknowledgement}

We are grateful to Mr. Dulal Nandi, Assistant Professor, Department of Biostatistics, Comilla University, Comilla for his kind co-operation in statistical analysis of data.

\section{References}

1. Surah Al Baqarah. The Holy Quran. Verses 183-185.

2. Ramachandran A, Snehalatha C, Wan Ma RC. Diabetes in South-East Asia: an update. Diabetes Res Clin Pract 2013: 103(2): 231- 237.

3. Rahim MA, Vaaler S, Ali SMK, Khan AK, Hussain A, Nahar Q. Prevalence of type 2 diabetes in urban slums of Dhaka, Bangladesh. Bangladesh Medical Res Council Bull 2004; 30(2): 60-70.

4. Rahim MA, Hussain A, Khan AKA, Nahar Q, Ali SM, Hussain A. Rising prevalence of type 2 diabetes in rural Bangladesh: a population based study. Diabetes Res Clini Practice 2007; 77(2): 300-305.

5. Sayeed MA, Mahtab H, Khanam PA, Ahsan KA, Banu A, Rashid AN et al. Diabetes and impaired fasting glycemia in the tribes of Khagrachari hill tracts of Bangladesh. Diabetes Care 2004; 27(5): 1054-1059.

6. Al-Arouj M, Khalil SA, Buse J, Fahdil I, Fahmy M, Hafez S et al. Diabetes Care 2010; 33: 1895-1902.

7. Iraki L, Bogdan A. Ramadan diet restrictions modify the circadian time structure in humans: a study on plasma gastrin, insulin, glucose, and calcium and gastric $\mathrm{pH}$. J Clin Endocrinol Metab 1997; 82: 1261-1273.

8. Salti IE, Be'nard B, Detournay M, Bianchi-Biscay M, Brigand CL, Voinet $\mathrm{C}$ et al. Results of the epidemiology of diabetes and Ramadan 1422/2001 (EPIDIAR) study. Diabetes Care 2004; 27(10): 2306-2311.

9. Rahman O, Islam MR. Association between fasting of Ramadan and risk factors of diabetes: a study from Rajshahi city in Bangladesh. Advance Journal of Food Science and Technology 2011; 3(5): 360-365.

10. Beshyah SA. Fasting during the month of Ramadan for people with diabetes: medicine and fiqh united at last. Ibnsina J Med Bio1 2009; 1(2): 58-60.

11. Bravis VE, Hui S, Salih S, Mehar S, Hassanein M, Devendra D. Ramadan education and awareness in diabetes programme for Muslims with type 2 diabetes who fast during Ramadan. Diabetes Med 2010; 27(3): 327-331.

12. Hassanein MM. Diabetes and Ramadan: how to achieve a safer fast for Muslims with diabetes. Br J Diabetes Vasc Dis 2010; 10: 246-250.

13. King H, Aubert RE, Herman WH. Global burden of diabetes, 1995-2025: prevalence, numerical estimates, and projections. Diabetes Care 1998; 21(9): 1414-1431.

14. Temizhan A, Donderici O, Ouz D, Demirbas B. Is there any effect of Ramadan fasting on acute coronary heart disease events? Int J Cardiol 1999; 70: 149-153.

15. Akhan G, Kutluhan S, Koyuncuoglu HR. Is there any change of stroke incidence during Ramadan? Acta Neurol Scand 2000; 101: 259-261.

16. Sulimani RA. Ramadan fasting medical aspects in health and disease. Ann Saudi Med 1991; 11: 637-641.

17. Toda M, Morimoto K. Effects of Ramadan fasting on the health of Muslims. Japanese Journal Of Hygiene 2000; 54: 592-596.

18. Aldouni A, Ghalim N. Fasting during Ramadan induces a marked increase in high-density lipoprotein-cholesterol and decrease in low-density lipoprotein cholesterol. Ann Nutr Metab 1997; 4: 242-249.

19. Temizhan A, Tandogan I, Doderici O, Demirbas B. The effects of Ramadan fasting on blood lipid levels. Am J Med 2000; 109: 341-342.

20. Fariduddin M. Ramadan and Diabetes. $4^{\text {th }}$ edn. Dhaka: Fariduddin, 2012: 21-26.

21. Friedewald WT, Levy RI, Fredrickson DS. Estimation of the concentration of low-density lipoprotein cholesterol in plasma without use of the preparative ultracentrifuge. Clinical Chemistry 1972; 18(6): 499-502.

22. Mafauzy M, Mohammed WB, Anum MY, Zulkifli A, Ruhani AH. A study of the fasting diabetic patients during the month of Ramadan. Med J Malaysia 1990; : 14-17.

23. Azizi F, Rasouli HA. Serum glucose, bilirubin, calcium, phosphorus, protein and albumin concentrations during Ramadan. Med J IR Iran 1987; 1: 38-41.

24. Rashed H. The fast of Ramadan: no problem for the well: the sick should avoid fasting. BMJ 1992; 304: 521-522.

25. Laajam MA. Ramadan fasting and non insulin-dependent diabetes: effect of metabolic control. East Afr Med J 1990; 67: 732-736.

26. Sulimani RA, Laajam M, Al-Attas O. The effect of Ramadan fasting on diabetes control in type II diabetic patients. Nutrition Research 1991; 11: 261-264.

27. Takruri HR. Effect of fasting in Ramadan on body weight. Saudi Med J 1989; 10: 491-494. 
28. Khaled BM, Belbraouet S. Effect of Ramadan fasting on anthropometric parameters and food consumption in 276 type 2 diabetic obese women. International Journal of Diabetes in Developing Countries 2009; 29(2): 62-68.

29. Chamakhi S, Ftouhi B, Ben Rahmoune N, Ghorbal S, Ben Khalifa F. Influence of the fast of Ramadan on the balance glycemic to diabetics. Medicographia 1991;13(Suppl 1): 27-29.

30. Hallak MH, Nomani MZA. Body weight loss and changes in blood lipid levels in normal men on hypocaloric diets during Ramadan fasting. The American Journal of Clinical Nutrition 1988; 48: 1197-1210.

31. Dehghan M, Nafarabadi M, Navai L, Azizi F. Effect of Ramadan fasting on lipid and glucose concentration in type 2 diabetes patients: Shaheed Beheshti University of Med Sciences, Tehran, IR Iran. J Faculty Med 1994; 18: 42-47.

32. Gumaa KA, Mustafa KY, Mahmoud NA, Gader AMA. The effects of fasting in Ramadan: serum uric acid and lipid concentrations. British Journal of Nutrition 1978; 40: 573-581.

33. Nagra SA, Rahman ZU. Study of some biochemical parameters in young women as affected by Ramadan fasting. International Journal of Ramadan Fasting Research 1998; 2(1): $1-5$.

34. Yarahmadi SH, Larijani B, Bastanhagh MH. Metabolic and clinical effects of Ramadan fasting in patients with T2D. Journal of the College of Physicians and Surgeons, Pakistan 2003; 13: 329-332.

35. Iacano J, Doughery R. Lack of effect of linoleic acid on the high density lipoprotein-cholesterol fraction of plasma lipoproteins. The American Journal of Clinical Nutrition 1991; 13: 154-161.
36. Khatib F. Effect of fasting in Ramadan on blood glucose and plasma lipids in diabetics with NIDDM. In: The $2^{\text {nd }}$ International Congress on Health and Ramadan, Istanbul, Turkey. December 1997; 1-3.

37. Toth PP. The "Good Cholesterol": high-density lipoprotein. Circulation 2005; 111: e89 - e91.

38. Mansi KMS. Study the effects of Ramadan fasting on the serum glucose and lipid profile among healthy Jordanian students. American Journal of Applied Sciences 2007; 4(8): 565-569.

39. Nomani MM, Hallak S, Siddiqui I. Changes in blood urea and glucose and their association with energy containing nutrients during Ramadan fasting. The American Journal of Clinical Nutrition 1989; 49: 1141-1145.

40. Larijani B, Zahedi F, Sanjari M, Amini MR, Jalili RB, Adibi $\mathrm{H}$ et al. The effect of Ramadan fasting on fasting serum glucose in healthy adults. Medical Journal of Malaysia 2003; 58(5): 678-680.

41. Mahboob, Sattarivand S, Nouri RM, Arefhosseni S. Effect of Ramadan fasting on serum lipid profiles in normal and hyperlipidemic subjects. Saudi Medical Journal 1999: 20(12): 947-950.

42. Azizi F, Siahkolah B. Ramadan fasting and diabetes mellitus. Archives of Iranian medicine 2003; 22: 186-191.

43. Ait Saada, Selselet D, Attou G, Kassoul S, Italhi M, Kati D. Effect of the Ramadan fasting on the variations of certain anthropometric and biochemical parameters in type 2 diabetic patients treated with medications mixture (biguanides and sulfamides). Advances in Biological Research 2008; 2(5-6): 111-120. 